\title{
Comparison of Certolizumab Pegol with Other Anticytokine Agents for Treatment of Rheumatoid Arthritis: A Multiple-treatment Bayesian Metaanalysis
}

\author{
ROBERT LAUNOIS, BERNARD AVOUAC, FRANCIS BERENBAUM, OLIVIER BLIN, ISABELLE BRU, \\ BRUNO FAUTREL, JEAN-MICHEL JOUBERT, JEAN SIBILIA, and BERNARD COMBE
}

\begin{abstract}
Objective. To compare the clinical efficacy of certolizumab pegol (CZP) with that of other anticytokine agents indicated for the treatment of rheumatoid arthritis (RA) with identical therapeutic indication (anti-tumor necrosis factor- $\alpha$, anti-interleukin 1 or 6 ), with the objective of determining the noninferiority of CZP.

Methods. A systematic review was performed to identify randomized controlled trials that assessed the efficacy of anticytokine agents in combination with conventional disease-modifying antirheumatic drugs (DMARD) after 6 months of treatment, using the American College of Rheumatology (ACR) response criteria, in patients with RA who have shown inadequate response to DMARD including methotrexate. Indirect treatment comparisons were carried out by a multiple-treatment Bayesian random-effects metaanalysis. Data were analyzed using the Markov chain Monte Carlo simulation. Noninferiority of CZP was assessed in comparison with a predefined equivalence margin of $5 \%$.

Results. Nineteen placebo-controlled studies were identified: 14 evaluated the efficacy of 5 anti-TNF- $\alpha$ agents (infliximab, etanercept, adalimumab, golimumab, CZP) and 5 evaluated efficacy of 2 anti-interleukin agents (anakinra, tocilizumab). Every treatment showed significant efficacy versus placebo in individual studies. The multiple-treatment metaanalysis showed a highest OR for CZP on ACR20 response. Metaanalysis indicates that the efficacy of CZP according to ACR20 response is superior to that of infliximab, adalimumab, and anakinra, and equivalent or superior to that of etanercept, golimumab, and tocilizumab. According to ACR50 response, the efficacy of CZP is equivalent or superior to that of all other anticytokines.

Conclusion. Results of this original multiple-treatment Bayesian metaanalysis indicate that certolizumab pegol is at least as efficacious as the preexisting antirheumatic anticytokine biotherapies. (First Release Jan 15 2011; J Rheumatol 2011;38:835-45; doi:10.3899/jrheum.100665)
\end{abstract}

Key Indexing Terms:

CERTOLIZUMAB PEGOL ANTI-TUMOR NECROSIS FACTOR- $\alpha$ ANTICYTOKINES BIOLOGICS RHEUMATOID ARTHRITIS MULTIPLE-TREATMENT METAANALYSIS

From the Evaluation Network for Health Economics (REES) France, Paris; Department of Rheumatology, Henri-Mondor Hospital, Créteil; Department of Rheumatology, Pierre et Marie Curie University, AP-HP Saint-Antoine Hospital, Paris; CIC-CPCET, UMR6193, Aix-Marseille University, La Timone Hospital, Marseille; Department of Rheumatology, AP-HP Pitié-Salpêtrière Hospital, Paris; Department of Rheumatology,

National Reference Centre for Autoimmune Diseases, Strasbourg University Hospitals, Strasbourg; Department of Rheumatology, Lapeyronie Hospital, Montpellier; and UCB Pharma, Colombes, France. Supported by UCB Pharma. Members of the study's Scientific Committee received consulting fees from UCB Pharma.

R. Launois, PhD, REES France; B. Avouac, MD, Henri-Mondor Hospital; F. Berenbaum, MD, PhD, Pierre et Marie Curie University, AP HP Saint-Antoine Hospital; O. Blin, MD, PhD, CIC-CPCET, La Timone Hospital, Aix-Marseille University; I. Bru, PharmD, UCB Pharma; B. Fautrel, MD, PhD, AP-HP Pitié-Salpêtrière Hospital; J-M. Joubert, MD, UCB Pharma; J. Sibilia, MD, Strasbourg University Hospitals; B. Combe, MD, PhD, Lapeyronie Hospital.

Address correspondence to Prof. B. Combe, Département de Rhumatologie, Hôpital Lapeyronie, 371 avenue du Doyen G. Giraud, 34295 Montpellier cedex 5, France.E-mail: b-combe@chu-montpellier.fr Full Release Article. For details, see Reprints/Permissions at jrheum.com Accepted for publication November 24, 2010.
Rheumatoid arthritis (RA) is a systemic disease characterized by chronic inflammation of the synovial lining of the joints, tendons, and periarticular structures. RA affects $0.3 \%$ to $1 \%$ of the population in Western countries ${ }^{1,2,3}$. If untreated, it leads to joint destruction and functional deterioration and considerable alteration of quality of life. The last decade saw the transition, for the treatment of RA, from general immunomodulators to biotherapies that specifically target cytokines [tumor necrosis factor- $\alpha$ (TNF- $\alpha)$, interleukins] or the immune system cells ( $\mathrm{T}$ and B lymphocytes) implicated in the pathogenesis of RA, with considerable improvement in treatment efficacy. The objective of RA therapy now is to reduce disease activity to a very low level or even achieve RA remission in an appreciable proportion of patients.

The first anti-TNF- $\alpha$ that were developed at the beginning of the 2000s (infliximab, etanercept, adalimumab) have been followed more recently by golimumab and certolizum-

Personal non-commercial use only. The Journal of Rheumatology Copyright @ 2011 . All rights reserved. 
ab pegol (CZP). CZP differs from the other anti-TNF- $\alpha$ by its structure, composed of the Fab' antigen-binding domain of a humanized monoclonal anti-TNF antibody combined with polyethylene glycol to increase its half-life in the body. Being free of the Fc portion of the antibody, CZP does not form immune complexes, does not activate complement, and does not induce antibody-dependent cytotoxicity ${ }^{4}$. Efficacy and safety of CZP have been demonstrated in the treatment of RA ${ }^{5,6}$. CZP, in combination with methotrexate (MTX), is indicated for the treatment of moderate to severe, active RA in adult patients when the response to disease-modifying antirheumatic drugs (DMARD), including MTX, has been inadequate. CZP can also be given as monotherapy in case of intolerance to MTX or when continued treatment with MTX is inappropriate ${ }^{7}$.

All these biotherapies have demonstrated clinical efficacy versus placebo in the treatment of RA. Few studies, however, have carried out head-to-head comparisons between anticytokine therapies or with other biologics, so that currently no actual estimation of their relative efficacies can be made. Therefore, only indirect comparisons (vs a common comparator $)^{8}$ make it possible to assess the differences possibly existing between antirheumatic biotherapies. Some recently published studies used multiple-treatment metaanalyses to compare the first marketed anti-TNF- $\alpha$ agents (infliximab, etanercept, adalimumab) either between them $^{9,10}$ or with another biological agent (abatacept, anakin$\mathrm{ra}$, or rituximab) ${ }^{11,12,13}$. Regarding the clinical efficacy of CZP, it still has not been compared with that of other anticytokine biotherapies [anti-TNF- $\alpha$, anti-interleukin 1 and 6] in a mixed-treatment comparison.

Our primary objective was to determine whether CZP is not inferior to the other anticytokines (anti-TNF- $\alpha$, anti-interleukin 1 and 6) used for the treatment of RA in combination with conventional DMARD, in patients that showed inappropriate or no response to conventional DMARD, including MTX.

\section{MATERIALS AND METHODS}

The method used was a mixed-treatment comparison model using Bayesian techniques. The study Scientific Committee, composed of 5 rheumatologists, a pharmacologist, and a health economist, defined the selection criteria and conducted the systematic literature review and data extraction.

Search strategy. A systematic literature review was carried out from January 1, 1980, to June 30, 2009, in the following databases: Medline (from 1996), Embase (from 1980), and Cochrane Library (Central Register of Controlled Trials, from 1993). This review was completed by a manual search in the proceedings of the American College of Rheumatology (ACR) and European League Against Rheumatism congresses since 2004.

Study selection. The studies searched were the controlled, randomized, double-blind trials published in the English language that included adult patients with RA who had an inadequate or no response to DMARD including MTX. In addition, the studies evaluated anticytokine biotherapies indicated for the treatment of RA versus placebo in combination with continuation of inadequate conventional DMARD. Biologics should be used according to their Summary of Product characteristics. Clinical efficacy should have been assessed by the ACR20, ACR50, and ACR70 response rates $^{14}$. ACR20 criterion, which characterizes a minimal therapeutic response and was the primary efficacy criterion used in the majority of studies, was retained as the major efficacy outcome in the multiple-treatment metaanalysis. ACR50 response, which possesses better clinical significance, and ACR70 response were used as secondary efficacy criteria. Efficacy evaluation had to be available at $24 \pm 8$ weeks of treatment. According to the defined inclusion criteria, studies were excluded from the analysis if they included patients with RA naive to DMARD or with inadequate or no response to a previous anti-TNF- $\alpha$, as well as those that did not report ACR20 rates after about 6 months of treatment.

The search protocol was thus compliant with the Patient/Population Intervention - Comparison/Comparator - Outcome criteria study (PICOS) detailed in the Preferred Reporting Items for Systematic reviews and Meta-Analyses (PRISMA) recommendations, and study results are presented according to the PRISMA statement ${ }^{15}$.

Data extraction. The key words used for the search were as follows: Arthritis Rheumatoid AND Infliximab OR Etanercept OR Adalimumab OR Certolizumab Pegol OR Golimumab OR Anakinra OR Tocilizumab. RA was searched in the Medical Subject Headings database as an exploded heading, and infliximab, etanercept, adalimumab, golimumab, CZP, anakinra, and tocilizumab as text words, because they are not currently indexed. The systematic review thus identified 6105 references.

Data extraction was then carried out by 2 independent reviewers. Article titles and abstracts were scrutinized, and the references that did not match eligibility criteria and duplicates were excluded. A total of 162 references were selected in this phase, and full-text copies were assessed in conformity with the study eligibility criteria. The references that did not meet eligibility criteria were excluded. Finally, 76 references corresponding to 19 trials were retained for the metaanalysis (Figure 1). The characteristics of patients included in these studies and study results were entered onto a dedicated database. To this end, a standardized extraction framework was completed by 2 reviewers, and any discrepancies were resolved by a third independent reviewer.

Evaluation of study quality. Methodological quality of the selected studies was assessed by the Jadad score (from 0 to 5), which is based on randomization, on whether the study was double-blind, and on the numbers of withdrawals and treatment cessations ${ }^{16}$. All studies included in the metaanalysis had a Jadad score of at least 3.

Data analysis. The relative efficacy of all studied treatments in comparison with a common comparator has been first determined by a classical frequentist method and expressed as the odds ratio of response rate on the considered criterion and the related confidence intervals.

Indirect comparisons between treatments were carried out by a multiple-treatment Bayesian random-effects metaanalysis of a network of direct comparisons (mixed-treatment comparison) ${ }^{8,17}$. The multiple-treatment random-effects model integrates, on the one hand, the information resulting from direct and/or indirect comparisons between treatments and on the other hand, the heterogeneity existing between the trials, in a randomeffects model that takes into account the variability of the measured effect between trials (between-trial variability may be caused by some unmeasured characteristics such as heterogeneity of patient populations or of methods of care $)^{18}$.

Bayesian analysis determines how newly available information changes expert opinion in relation to the previous situation. It thus requires an estimation of a prior probability distribution of the considered variable on the basis of the preexisting information, and a separate estimation of its distribution according to the new data (likelihood). It then updates the prior distribution using the likelihood to obtain the posterior probability distribution. The Bayesian analysis finally describes the spreading of the degrees of credibility of the possible values of the considered measurement. Results are described by the mean and related credible interval $(\mathrm{CrI})^{19}$. Practically, we used normal (mean 0 , precision 0.00001 ) prior distributions for all population means, and noninformative uniform $(0,10)$ prior distributions for all variances to allow the data, rather than the prior distributions, to have a

Personal non-commercial use only. The Journal of Rheumatology Copyright ( 2011 . All rights reserved. 


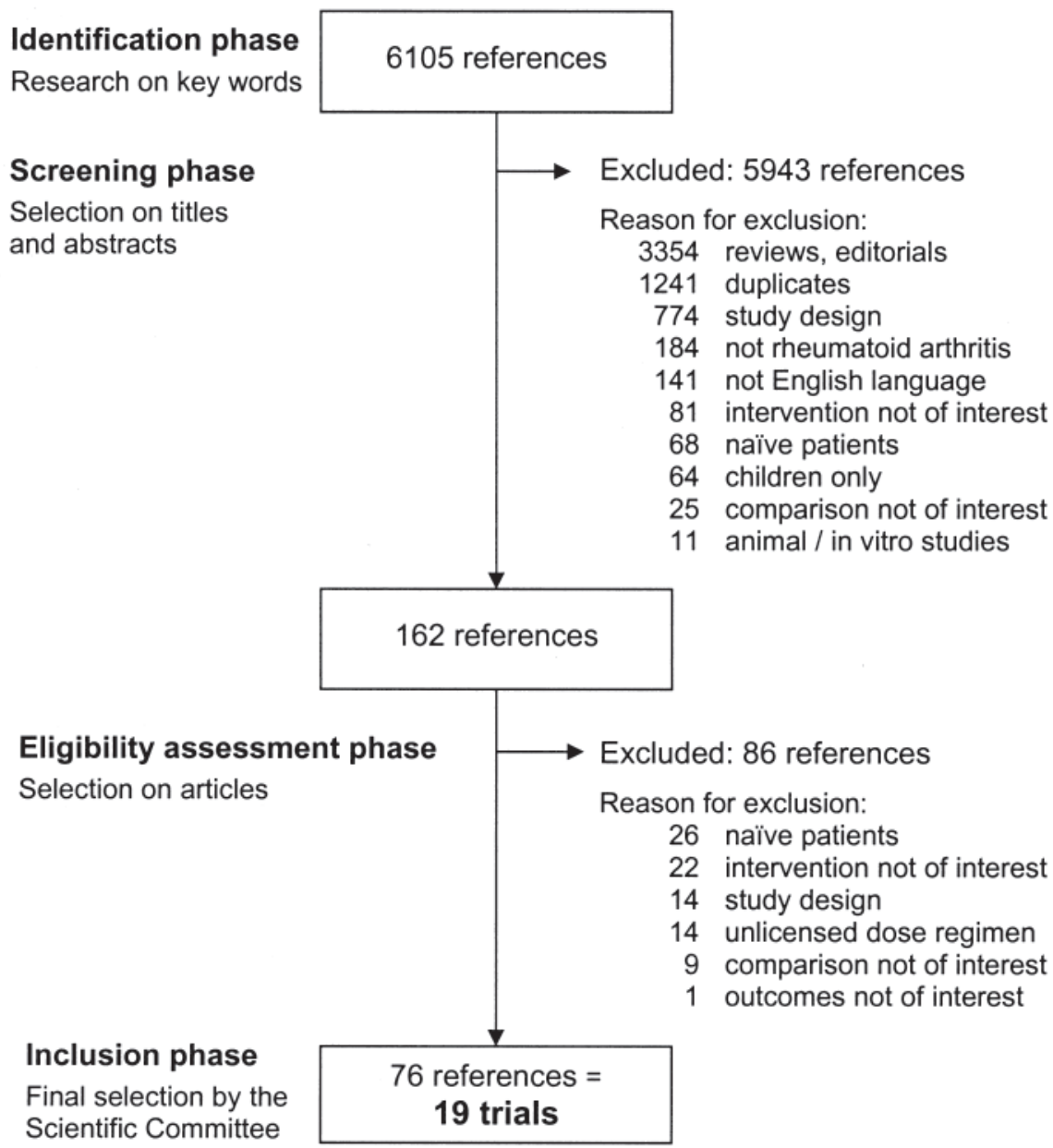

Figure 1. Selection procedure for a multiple-treatment metaanalysis from January 1980 to June 2009.

stronger influence on the results. The absolute probability of success of each treatment (which represents its absolute efficacy) has been evaluated, that of the common comparator being estimated by the mean of responses in all studies. Since OR for each treatment were determined in comparison with a common comparator, randomization was not broken and it is possible to compare the efficacy estimates of all studied treatments.

For the assessment of CZP noninferiority in comparison with other treatments, the Scientific Committee defined an a priori absolute difference margin of 5\% (or 0.05 ) in response rate (absolute value) versus every comparator (placebo or active treatment) and for every evaluation criterion (ACR20, ACR50, and ACR70). The 5\% value corresponds to the clinically relevant threshold regarding the expected effects for all treatments. Calculations were performed using the measurement "absolute efficacy," i.e., the relative efficacy of each treatment tested in comparison with the baseline treatment (DMARD), with the mean effect of the baseline treatment across all trials added. For each pairwise comparison, the estimation of noninferiority was determined in 2 steps: first, the log-OR of the lower limit of the predefined absolute risk equivalence margin versus the mean absolute efficacy of the comparator(s) was computed to obtain the noninferiority threshold. Second, the probability for the log-OR absolute efficacy of CZP being superior or equal to this log-OR threshold was then obtained directly by applying the Markov chain Monte Carlo method, which gave the probability of CZP being noninferior to the comparator according to the posterior distribution of the Bayesian analysis. The probability of CZP noninferiority has been estimated in comparison with each active treatment as well as in comparison with the mean of all other treatments. The noninferiority was thereby inferred at a posterior probability of $\geq 0.975$ (corresponding to a conventional 1 -sided probability $\leq 0.025$ ).

Further, if noninferiority had been demonstrated, superiority in between-drug relative efficacy comparisons was assessed from comparisons of the lower and superior limits of the OR credible intervals determined on the basis of the posterior distribution.

Statistical analyses were performed by REES (Evaluation Network in Health Economics) with WinBUGS software (Bayesian Inference Using Gibbs Sampling), using Markov chain Monte Carlo simulation for the calculation of the multidimensional integrals that arise in Bayesian statistics ${ }^{20}$.

\section{RESULTS}

Selected studies. Nineteen studies were selected in accordance with the predefined criteria and entered into the multiple-treatment metaanalysis $5,6,21,22,23,24,25,26,27,28,29,30,31$, 32,33,34,35,36,37 (Figure 1).

All the selected randomized studies were comparative versus placebo (therefore the common comparator of the multiple-treatment metaanalysis): 14 of them evaluated the efficacy of an anti-TNF- $\alpha$ therapy (infliximab, etanercept, adalimumab, golimumab, CZP) and 5 an anti-interleukin 
treatment (anakinra, tocilizumab). The metaanalysis thus involves a total of 7158 patients, of whom 3174 received placebo and 3984 received an anticytokine treatment: 698 were treated with infliximab in 4 studies, 160 with etanercept in 2 studies, 657 with adalimumab in 4 studies, 124 with golimumab in 2 studies, 639 with CZP in 2 studies, 250 with anakinra in 1 study, and 1456 with tocilizumab in 4 studies. The evidence network made up of the 19 selected studies enables comparison between the 7 treatments tested. The chain of evidence was continuous and all treatments were compared with another analyzed treatment, in this case placebo.

Characteristics of studies, patients, and treatments. In most studies, the DMARD combined with active treatment or placebo was MTX (17 studies). In 2 studies, the combined DMARD was sulfasalazine ${ }^{26}$ or any standard DMARD ${ }^{30}$. The populations of patients included in the different studies were homogeneous regarding age and functional score as measured by the Health Assessment Questionnaire (HAQ; Table 1$)^{38}$. The proportion of patients who were positive for rheumatoid factor (RF) was generally high (> 70\%), except for 2 studies of adalimumab ${ }^{29,30}$. In contrast, RA duration differed between studies (median 8 years; range 5-13 years): it was somewhat longer ( $\geq 10$ years) in 6 relatively old studies (published from 1999 to 2005) and somewhat shorter ( $\leq 7$ years) in 6 more recent studies (published in

Table 1. Characteristics of patients included in the selected studies.

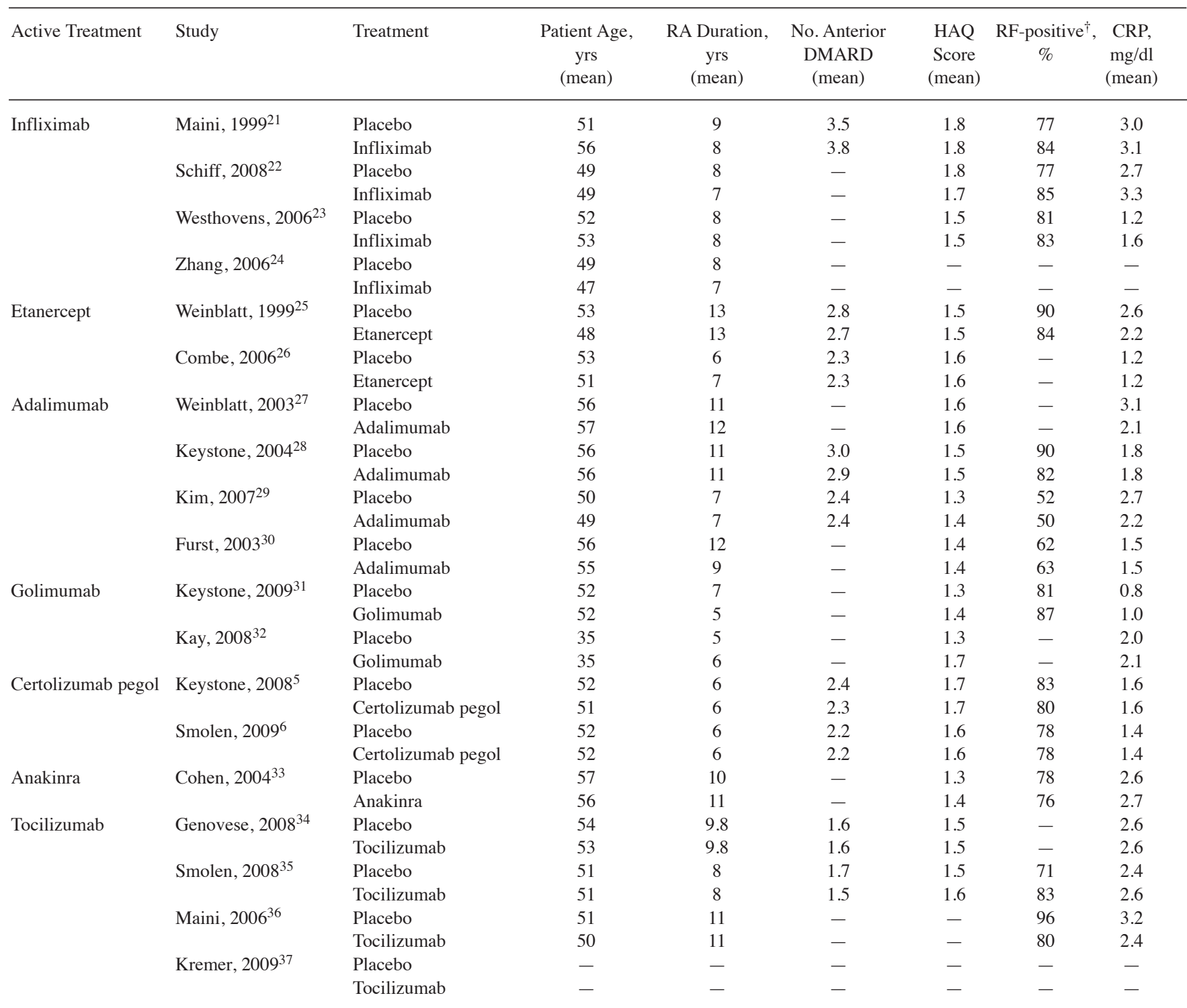

DMARD: disease-modifying antirheumatic drug; CRP: C-reactive protein; ${ }^{\dagger}$ RF-positive: patients positive for rheumatoid factor; HAQ: Health Assessment Questionnaire; RA: rheumatoid arthritis. 
2008 and 2009). These differences between studies were indicative of some level of heterogeneity between the populations of patients included in the older and those included in the more recent studies.

Efficacy of treatments in each individual study. Efficacy results observed in patients receiving the active treatment or placebo, according to the ACR20, ACR50, and ACR70 response criteria, are presented in Table 2 . The relative efficacies of all treatments in comparison with placebo, as measured by the OR and the associated 95\% CI in each study, are presented in Table 3. In all studies (except a study of golimumab), OR demonstrated significant efficacy versus placebo for all treatments on the ACR20 response (primary evaluation criterion). OR also demonstrated marked effica- cy versus placebo for all treatments on the secondary criterion ACR50. Relative efficacy on the ACR70 response could not be determined in 4 studies ${ }^{21,25,32,37}$.

Mixed-treatment comparison. Results of the multiple-treatment metaanalysis, regarding the efficacy of each treatment on the ACR20, ACR50, and ACR70 response criteria in comparison with the common comparator (placebo), in the random effects and fixed- effects models, are presented in Table 4, and results in the random-effects model are depicted in Figure 2. Because of insufficient numbers of patients, the OR on the ACR70 response calculated for etanercept, golimumab, and anakinra gave very wide credible intervals and thus were considered not interpretable.

In the metaanalysis according to the random-effects

Table 2. Raw results: numbers of patients achieving the efficacy criteria ACR20, ACR50, and ACR70.

\begin{tabular}{|c|c|c|c|c|c|c|}
\hline Active Treatment & Study & Treatment & $\begin{array}{l}\text { No. Patients } \\
\text { Included }\end{array}$ & $\begin{array}{c}\text { ACR20, } \\
\text { n (\%) }\end{array}$ & $\begin{array}{c}\text { onding Pati } \\
\text { ACR50, } \\
\text { n }(\%)\end{array}$ & $\begin{array}{c}\text { ACR70, } \\
\text { n (\%) }\end{array}$ \\
\hline \multirow{5}{*}{ Infliximab } & Maini $^{21}$ & Infliximab & 86 & $43(50)$ & $22(26)$ & $7(8)$ \\
\hline & \multirow[t]{2}{*}{ Schiff 22} & Placebo & 110 & $46(42)$ & $22(20)$ & $10(9)$ \\
\hline & & Infliximab & 165 & $98(59)$ & $61(37)$ & $40(24)$ \\
\hline & \multirow[t]{2}{*}{ Zhang $^{24}$} & Placebo & 86 & $42(49)$ & $22(26)$ & $12(14)$ \\
\hline & & Infliximab & 87 & $66(76)$ & $38(44)$ & $20(23)$ \\
\hline \multirow[t]{4}{*}{ Etanercept } & \multirow[t]{2}{*}{ Weinblatt $^{25}$} & Placebo & 30 & $8(27)$ & $1(3)$ & $0(0)$ \\
\hline & & Etanercept & 59 & $42(71)$ & $23(39)$ & $9(15)$ \\
\hline & \multirow[t]{2}{*}{ Combe ${ }^{26}$} & Placebo & 50 & $14(28)$ & $7(14)$ & $1(2)$ \\
\hline & & Etanercept & 101 & $75(74)$ & $53(52)$ & $25(25)$ \\
\hline \multirow{4}{*}{ Adalimumab } & \multirow[t]{2}{*}{$\mathrm{Kim}^{29}$} & Placebo & 63 & $23(37)$ & $9(14)$ & $5(8)$ \\
\hline & & Adalimumab & 65 & $40(62)$ & $28(43)$ & $14(22)$ \\
\hline & \multirow[t]{2}{*}{ Furst $^{30}$} & Placebo & 318 & $111(35)$ & $36(11)$ & $11(4)$ \\
\hline & & Adalimumab & 318 & $168(53)$ & $92(29)$ & 48 (15) \\
\hline \multirow[t]{4}{*}{ Golimumab } & \multirow[t]{2}{*}{ Keystone $^{31}$} & Placebo & 133 & 37 (28) & $18(14)$ & $7(5)$ \\
\hline & & Golimumab & 89 & $53(60)$ & $33(37)$ & $18(20)$ \\
\hline & \multirow[t]{2}{*}{ Kay $^{32}$} & Placebo & 35 & $13(37)$ & $2(6)$ & $0(0)$ \\
\hline & & Golimumab & 35 & $21(60)$ & $13(37)$ & $3(9)$ \\
\hline \multirow[t]{4}{*}{ Certolizumab pegol } & \multirow[t]{2}{*}{ Keystone $^{5}$} & Placebo & 199 & $27(14)$ & $15(8)$ & $6(3)$ \\
\hline & & Certolizumab pegol & 393 & $231(59)$ & $146(37)$ & $84(21)$ \\
\hline & \multirow[t]{2}{*}{ Smolen $^{6}$} & Placebo & 127 & $11(9)$ & $4(3)$ & $1(1)$ \\
\hline & & Certolizumab pegol & 246 & $141(57)$ & $80(33)$ & $39(16)$ \\
\hline \multirow{2}{*}{ Tocilizumab } & \multirow[t]{2}{*}{ Kremer $^{37}$} & Placebo & 393 & $106(27)$ & - & - \\
\hline & & Tocilizumab & 398 & $223(56)$ & - & - \\
\hline
\end{tabular}

ACR: American College of Rheumatology. 
Table 3. Raw results: relative efficacy vs placebo on ACR20, ACR50, and ACR70 response criteria.

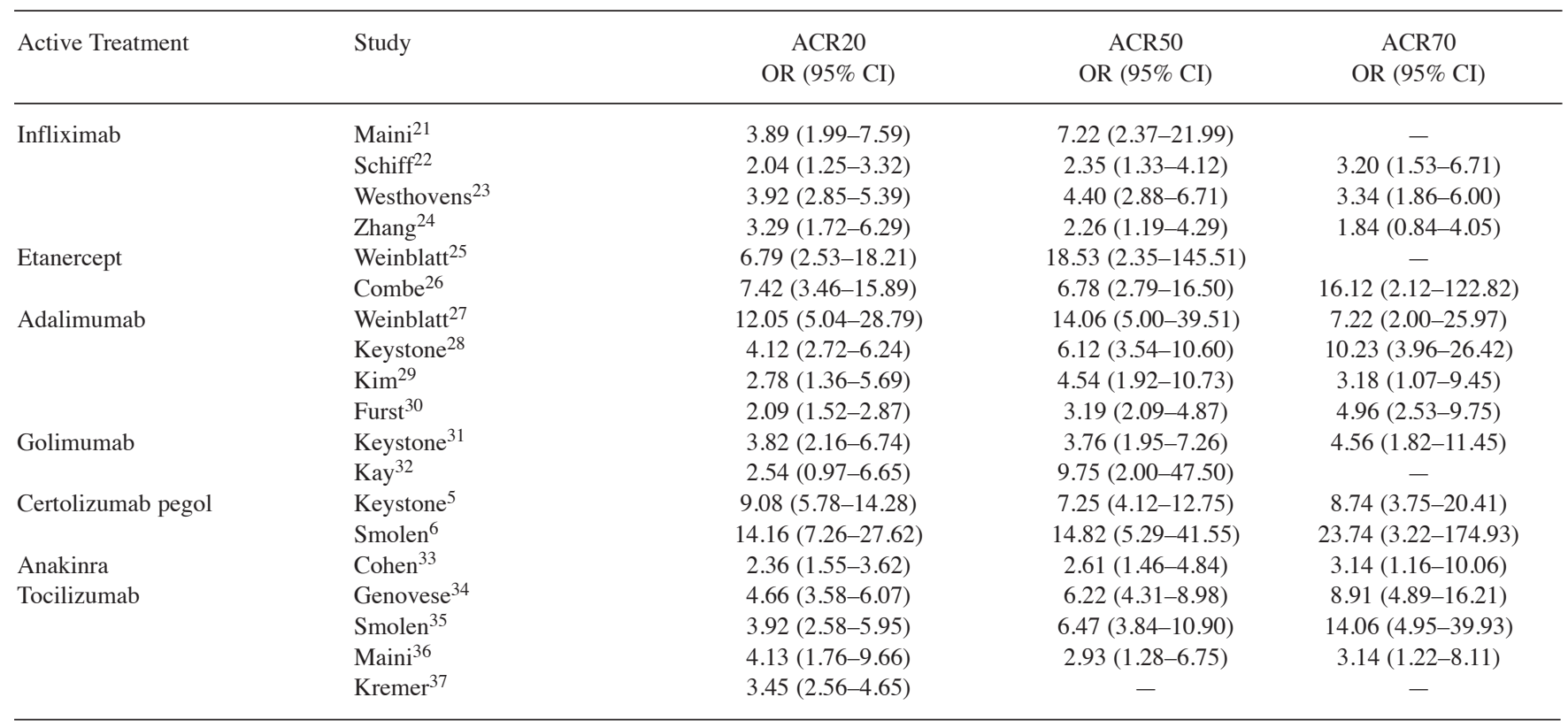

ACR: American College of Rheumatology.

Table 4. Relative efficacy of each treatment vs placebo in the mixed-treatment metaanalysis.

\begin{tabular}{lccc}
\hline Treatment & ACR20 & ACR50 & ACR70 \\
& OR (95\% CrI) & OR (95\% CrI) & OR (95\% CrI) \\
\hline & & Random-effects Model & \\
Infliximab & $3.31(2.05-5.03)$ & $3.59(1.97-6.13)$ & $3.55(1.77-7.15)$ \\
Etanercept & $8.07(3.34-16.75)$ & $11.45(3.45-31.02)$ & $-*$ \\
Adalimumab & $3.72(2.35-5.93)$ & $5.66(3.15-10.01)$ & $6.63(3.12-12.69)$ \\
Golimumab & $3.62(1.62-6.97)$ & $5.72(2.07-13.69)$ & $-*$ \\
Certolizumab pegol & $11.82(5.98-21.71)$ & $10.81(4.41-24.02)$ & $15.84(4.64-43.89)$ \\
Anakinra & $2.40(0.96-5.03)$ & $2.84(0.81-7.26)$ & $-*$ \\
Tocilizumab & $4.13(2.64-6.19)$ & $5.68(2.78-9.93)$ & $8.63(3.70-16.99)$ \\
& & Fixed-effects Model & \\
Infliximab & $3.36(2.65-4.20)$ & $3.51(2.62-4.63)$ & $3.18(2.12-4.63)$ \\
Etanercept & $7.79(4.07-13.86)$ & $9.76(4.09-21.19)$ & $-*$ \\
Adalimumab & $3.12(2.46-3.89)$ & $4.87(3.58-6.54)$ & $6.26(3.89-9.74)$ \\
Golimumab & $3.61(2.14-5.76)$ & $4.77(2.52-8.38)$ & $-*$ \\
Certolizumab pegol & $10.94(7.42-15.81)$ & $9.43(5.60-15.43)$ & $12.83(5.61-28.08)$ \\
Anakinra & $2.24(1.49-3.26)$ & $2.53(1.39-4.32)$ & $-*$ \\
Tocilizumab & $4.09(3.43-4.86)$ & $5.92(4.47-7.79)$ & $8.48(5.37-13.06)$ \\
\hline
\end{tabular}

* Insufficient numbers of patients. ACR: American College of Rheumatology. CrI: credible interval.

model (which takes heterogeneity into account), efficacy results show relatively high OR on the ACR20 criterion for all treatments except anakinra. CZP exhibits the highest OR value (11.82; 95\% CrI 5.98-21.71): credible intervals indicate that the OR for CZP is significantly higher than that of infliximab (3.31; 95\% CrI 2.05-5.03), adalimumab (3.72; 95\% CrI 2.35-5.93), and anakinra (2.40; 95\% CrI 0.96-5.03) but not significantly different from that of the other biotherapies: etanercept $(8.07$; 95\% CrI 3.34-16.75), golimumab $(3.62 ; 95 \%$ CrI 1.62-6.97), and tocilizumab (4.13; 95\% CrI 2.64-6.19; Table 4, Figure 2). Regarding the
ACR50 criterion, CZP exhibits a high OR $(10.81 ; 95 \%$ CrI 4.41-21.02), comparable to that of etanercept $(11.45,95 \%$ CrI 3.45-31.02) and markedly but not significantly higher than that of every other treatment. As concerns the ACR70 criterion, CZP exhibits the highest OR $(15.8 ; 95 \% \mathrm{CrI}$ 4.64-43.89), which is not significantly different from those of the other treatments because of large credible intervals.

In the metaanalysis according to the fixed-effects model (which does not take into account heterogeneity between the studies), efficacy results similarly show, for all treatments, relatively high $\mathrm{OR}$ in comparison with placebo on the 

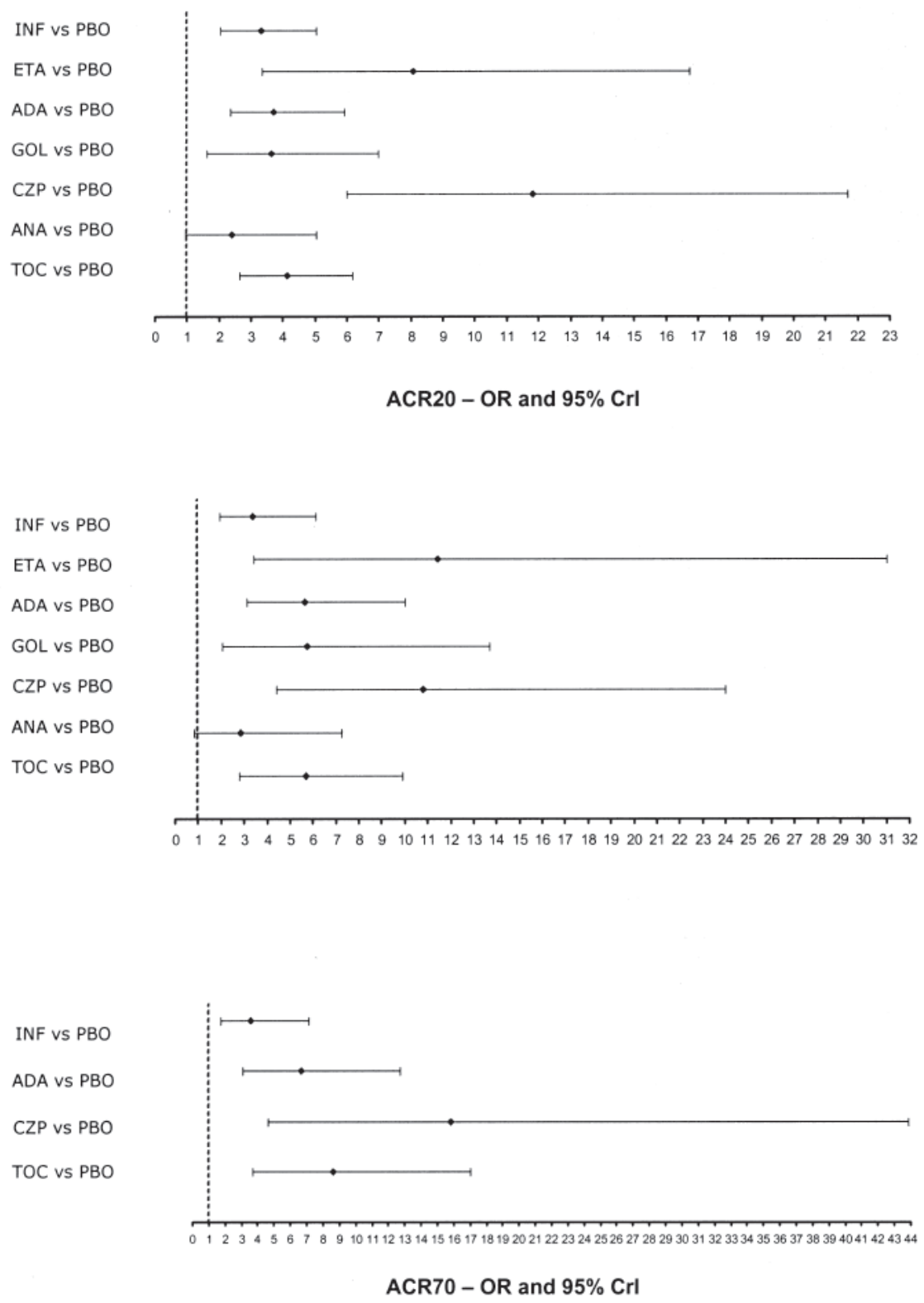

Figure 2. Odds ratios of the ACR20, ACR50, and ACR70 responses (random-effects model). ACR: American College of Rheumatology; ADA: adalimumab; ANA: anakinra; CZP: certolizumab pegol; ETA: etanercept; GOL: golimumab; INF: infliximab; PBO: placebo; TOC: tocilizumab; CrI: credible interval.

ACR20 criterion (primary efficacy criterion). CZP exhibits the highest OR value, which is significantly higher than those of the other treatments except etanercept. Regarding the ACR50 criterion, for CZP the OR appears significantly higher than those of infliximab and anakinra. As for the ACR70 criterion, CZP exhibits the highest OR, which is significantly higher than that of infliximab but not significantly different from those of other biotherapies (Table 4).

Noninferiority analysis. Results of the noninferiority analysis according to the random-effects and fixed-effects models are presented in Table 5. Regarding the ACR20 response, the probability of CZP being not inferior to the mean of all treatments or to each other individual biotherapy is high and significant (probability over 99\% vs all other biotherapies in the random-effects model and $100 \%$ in the fixed-effects model), except versus etanercept (compared to etanercept, the probability for CZP being not inferior is $>90 \%$ in the random-effects model and $>95 \%$ in the fixed-effects model). Regarding the ACR50 criterion, results again indicate high probability for CZP being not inferior to the mean of all treatments or each other individual biotherapy except etanercept, but noninferiority is significantly demonstrated only versus infliximab and anakinra in the random-effects model. Finally, regarding the ACR70 criterion, CZP nonin- 
Table 5. Results of the noninferiority analysis.

\begin{tabular}{|c|c|c|c|}
\hline \multirow{2}{*}{$\begin{array}{l}\text { Efficacy } \\
\text { Criteria }\end{array}$} & \multirow[t]{2}{*}{ Comparator } & \multicolumn{2}{|c|}{ Probability of Noninferiority } \\
\hline & & $\begin{array}{l}\text { Random-effects } \\
\text { Model }\end{array}$ & $\begin{array}{c}\text { Fixed-effects } \\
\text { Model }\end{array}$ \\
\hline \multirow[t]{7}{*}{ ACR20 } & Mean of all treatments & 0.999 & 1.0 \\
\hline & Infliximab & 1.0 & 1.0 \\
\hline & Etanercept & 0.901 & 0.951 \\
\hline & Adalimumab & 0.998 & 1.0 \\
\hline & Golimumab & 0.996 & 1.0 \\
\hline & Anakinra & 0.998 & 1.0 \\
\hline & Tocilizumab & 0.998 & 1.0 \\
\hline \multirow[t]{7}{*}{ ACR50 } & Mean of all treatments & 0.929 & 0.989 \\
\hline & Infliximab & 0.992 & 1.0 \\
\hline & Etanercept & 0.634 & 0.682 \\
\hline & Adalimumab & 0.948 & 0.998 \\
\hline & Golimumab & 0.925 & 0.989 \\
\hline & Anakinra & 0.991 & 1.0 \\
\hline & Tocilizumab & 0.950 & 0.990 \\
\hline \multirow[t]{6}{*}{ ACR70 } & Mean of all treatments & 0.539 & 0.501 \\
\hline & Infliximab & 0.995 & 1.0 \\
\hline & Etanercept & $*$ & $*$ \\
\hline & Adalimumab & 0.956 & 0.987 \\
\hline & Golimumab & $*$ & $*$ \\
\hline & Tocilizumab & 0.891 & 0.917 \\
\hline
\end{tabular}

* Insufficient numbers of patients.

feriority is significantly demonstrated only versus infliximab (Table 5).

\section{DISCUSSION}

The anticytokine biotherapies that have been marketed since the beginning of the 2000s (anti-TNF- $\alpha$ and anti-interleukin therapies) have greatly advanced medical management of RA. Numerous controlled studies demonstrated their outstanding efficacy in patients with RA who do not respond adequately to conventional DMARD: they reduce the rate of progression of joint damage ${ }^{39}$ and improve physical functioning ${ }^{38}$ as well as patient quality of life ${ }^{40}$.

CZP is a novel anti-TNF- $\alpha$ agent, composed of the Fab' domain of a monoclonal anti-TNF- $\alpha$ antibody coupled with 2 molecules of polyethylene glycol that do not interfere with the binding to TNF- $\alpha$ but increase certolizumab half-life in the body. Clinical studies indicate that the CZP safety and tolerability profile is favorable 5,6 .

Our metaanalysis compared CZP with 4 anti-TNF- $\alpha$ agents (infliximab, etanercept, adalimumab, golimumab) and 2 anti-interleukins (anakinra, tocilizumab), with a view to establishing the noninferiority of CZP in comparison with these RA treatments, in populations of patients corresponding to the approved therapeutic indication of CZP. It was carried out based on a selection of 19 placebo-controlled studies with similar protocols undertaken in patients receiving a concomitant conventional DMARD (essentially MTX). All active treatments demonstrated significant efficacy versus placebo on the ACR20 and ACR50 response cri- teria in every study (except for golimumab, which showed no significant efficacy on the ACR20 criteria in a study ${ }^{32}$ ). Infliximab was not significantly efficacious on the ACR70 criteria in a study.

Since currently no head-to-head study has directly compared the various anticytokine biotherapies, indirect comparisons have been performed but none included the recent biotherapies. The metaanalyses by Kristensen, et al and Nixon, et al concluded to equal efficacy for 3 anti-TNF- $\alpha$ agents: infliximab, etanercept, and adalimumab ${ }^{9,11}$, while that by Alonzo-Ruiz, et al determined equal efficacy for etanercept or adalimumab and MTX ${ }^{10}$. In contrast, 2 metaanalyses determined the superiority of anti-TNF- $\alpha$ agents in comparison with anakinra ${ }^{11,13}$.

The multiple-treatment metaanalysis carried out according to a random-effects model found that CZP exhibits high efficacy on the ACR20 criterion (primary efficacy criterion). Observation of the credible intervals indicates significantly superior efficacy for CZP in comparison with infliximab, adalimumab, and anakinra, and no different efficacy in comparison with the other anticytokine biotherapies tested (etanercept, golimumab, tocilizumab). In contrast to literature data, in this multiple-treatment metaanalysis, no anti-TNF- $\alpha$ agent tested apart from CZP was found to be significantly better than anakinra, which itself did not prove significantly better than placebo (Table 4). It is noteworthy that we included only 1 study of anakinra in our multiple-treatment metaanalysis. Regarding the secondary criteria ACR50 and ACR70, although CZP exhibited similar efficacy to etanercept, no significant difference between treatments emerged because of the width of the credible intervals. These differences from other metaanalyses may be related to the populations of patients studied (only patients with RA who had inadequate or no response to MTX in our metaanalysis) and perhaps to the limited number of studies available for some treatments, owing to the strict selection criteria applied for inclusion in our metaanalysis.

The multiple-treatment metaanalysis according to the fixed-effects model shows similar differences in OR between the treatments tested, with a higher number of significant between-treatment differences, however (because the fixed-effects model does not take heterogeneity between studies into account, the credible intervals are narrower). Results suggest greater efficacy for CZP on the ACR20 response criterion in comparison with all other treatments except for etanercept.

Results from the multiple-treatment metaanalysis according to the fixed-effects model should be taken with caution, however, in view of the existence of heterogeneities between the studies included in the metaanalysis, in particular regarding disease duration at entry to the study, which ranged from 6 to 13 years in the different groups of patients for the studies published before 2006, and from 5 to 11 years for those published after 2006. The 2 studies performed with 
CZP are among those most recently published ${ }^{5,6}$. Since RA is a progressive disease, disease duration is linked in some way to disease severity [as attested by the related differences in C-reactive protein (CRP) level], and this source of heterogeneity between studies performed at different times should be taken into account when assessing the relative efficacy of treatments in comparison with a common comparator (in our case, placebo) ${ }^{41}$. Such declines in time of disease duration at entry to clinical studies of antirheumatic biotherapies probably reflect the progressively increasing confidence of physicians in the safety of these novel treatments, while being also a probable consequence of international recommendations encouraging institution of active disease management as soon as possible after RA diagnosis ${ }^{42,43}$.

Nonetheless, since heterogeneity between studies is taken into account in multiple-treatment metaanalysis according to the random-effects model, CZP appears to be at least as efficacious as all other treatments tested (anti-TNF- $\alpha$ agents, anticytokines) and is possibly more efficacious than some of them (infliximab, adalimumab, anakinra) on the primary efficacy criterion ACR20.

Our ultimate objective was to test the hypothesis of noninferiority of the new anti-TNF- $\alpha$ agent CZP in comparison to the existing anticytokine antirheumatic biotherapies (anti-TNF- $\alpha$, anti-interleukins). This was a new approach not previously undertaken to our knowledge. Our analysis reinforces the conclusions of the metaanalysis. Data from our multiple-treatment Bayesian metaanalysis, taking into account the predefined noninferiority margin of $5 \%$, show that CZP is not inferior to any other biotherapies except etanercept on the primary efficacy criterion ACR20, with very high probability in both the random-effects and the fixed-effects models (probability over 99\% and 100\%, respectively). Compared to etanercept, the probability of CZP being not inferior could not be demonstrated statistically. Regarding the secondary criteria ACR50 and ACR70, the probability of noninferiority of CZP in comparison with the other biotherapies tested is also very high, except for etanercept.

Proper interpretation of the results of our metaanalysis requires consideration of some of its features. All clinical studies included were published in the English language. Although this could be considered a selection bias, practically all international studies are published in English. Regarding CZP, data come from only 2 studies, which nevertheless included relatively large numbers of patients, in comparison with the studies of other biotherapies (e.g., etanercept, golimumab). Those 2 studies are relatively recent and, for the reasons detailed, included patients with RA who had less severe disease (as suggested by relatively low CRP levels) than the patients included in older studies performed with other biotherapies. Further, these 2 studies differed from other studies by the low ACR20 rate of response to placebo $(<15 \%)$, which is lower than that generally observed in studies of other biotherapies (15\% to $49 \%$ ). Such a low response rate to placebo may have boosted CZP's apparent clinical efficacy. These between-study differences have been taken into account in our multiple-treatment metaanalysis according to the random-effects model. Yet, further clinical studies of CZP are required to confirm our results. Finally, the data in our metaanalysis pertained only to clinical efficacy of the analyzed treatments as assessed by ACR scores. Radiographic data were not included, because radiographic scores were either not obtained by identical methods or not available for all products. A more comprehensive evaluation of the different biotherapies used for the treatment of RA might also include information about their respective safety and tolerability profiles.

The mixed-treatment comparison of the clinical efficacy of CZP in the treatment of RA with that of 6 other anticytokine biotherapies supports with high statistical probability the hypothesis of noninferiority of CZP and suggests that $\mathrm{CZP}$ is at least as efficacious as the preexisting rheumatic anticytokine biotherapies. Studies in real-life conditions such as pragmatic assays should be done to confirm these results. This would reinforce our analysis by providing additional information about therapeutic strategies and biotherapy use in the outpatient and inpatient settings.

\section{ACKNOWLEDGMENT}

We thank for their active contribution Jean-Gabriel Lemoine, statistician at REES France, Jacques Legeai, PharmD, PhD, medical writer at Redasciences-Santé France, Hélène Herman-Demars, MD, immunology therapeutic area director at UCB Pharma SA, and Florent Richy, PhD, head of epidemiology at UCB Pharma SA.

\section{REFERENCES}

1. Spector TD. Rheumatoid arthritis. Rheum Dis Clin North Am 1990;16:513-37.

2. Guillemin F, Saraux A, Guggenbuhl P, Roux CH, Fardellone P, Le Bihan E, et al. Prevalence of rheumatoid arthritis in France: 2001. Ann Rheum Dis 2005;64:1427-30.

3. Roux CH, Saraux A, Le Bihan E, Fardellone P, Guggenbuhl P, Fautrel B, et al. Rheumatoid arthritis and spondyloarthropathies: geographical variations in prevalence in France. J Rheumatol 2007;34:117-22.

4. Nesbitt A, Fossati G, Bergin M, Stephens P, Stephens S, Foulkes R, et al. Mechanism of action of certolizumab pegol (CDP870): in vitro comparison with other anti-tumor necrosis factor alpha agents. Inflamm Bowel Dis 2007;13:1323-32.

5. Keystone E, Heijde D, Mason D Jr, Landewé R, Vollenhoven RV, Combe B, et al. Certolizumab pegol plus methotrexate is significantly more effective than placebo plus methotrexate in active rheumatoid arthritis: findings of a fifty-two-week, phase III, multicenter, randomized, double-blind, placebo-controlled, parallel-group study. Arthritis Rheum 2008;58:3319-29.

6. Smolen J, Landewé RB, Mease P, Brzezicki J, Mason D, Luijtens K, et al. Efficacy and safety of certolizumab pegol plus methotrexate in active rheumatoid arthritis: the RAPID 2 study. A randomised controlled trial. Ann Rheum Dis 2009;68:797-804.

7. Cimzia ${ }^{\circledR}$ summary of products characteristics. [Internet. Accessed

Personal non-commercial use only. The Journal of Rheumatology Copyright @ 2011 . All rights reserved. 
Nov 25, 2010]. Available from:

http://www.ema.europa.eu/ema/index.jsp?curl=pages/medicines/hum an/medicines/001037/human_med_001294.jsp\&mid=WC0b01ac058 001d124\&murl=menus/medicines/medicines.jsp

8. Sutton A, Ades AE, Cooper N, Abrams K. Use of indirect and mixed treatment comparisons for technology assessment.

Pharmacoeconomics 2008;26:753-67.

9. Kristensen LE, Christensen R, Bliddal H, Geborek P, Danneskiold-Samsøe B, Saxne T. The number needed to treat for adalimumab, etanercept, and infliximab based on ACR50 response in three randomized controlled trials on established rheumatoid arthritis: a systematic literature review. Scand J Rheumatol 2007;36:411-7.

10. Alonso-Ruiz A, Pijoan JI, Ansuategui E, Urkaregi A, Calabozo M, Quintana A. Tumor necrosis factor alpha drugs in rheumatoid arthritis: systematic review and metaanalysis of efficacy and safety. BMC Musculoskelet Disord 2008;9:52.

11. Nixon R, Bansback N, Brennan A. The efficacy of inhibiting tumour necrosis factor alpha and interleukin 1 in patients with rheumatoid arthritis: a meta-analysis and adjusted indirect comparisons. Rheumatology 2007;46:1140-7.

12. Venkateshan SP, Sidhu S, Malhotra S, Pandhi P. Efficacy of biologicals in the treatment of rheumatoid arthritis: a meta-analysis. Pharmacology 2009;83:1-9.

13. Singh JA, Christensen R, Wells GA, Suarez-Almazor ME, Buchbinder R, Lopez-Olivo MA, et al. Biologics for rheumatoid arthritis: an overview of Cochrane reviews. Cochrane Database Syst Rev 2009;4:CD007848.

14. Felson DT, Anderson JJ, Boers M, Bombardier C, Furst D, Goldsmith C, et al. American College of Rheumatology. Preliminary definition of improvement in rheumatoid arthritis. Arthritis Rheum 1995;38:727-35.

15. Liberati A, Altman DG, Tetzlaff J, Mulrow C, Gøtzsche PC, Ioannidis JP, et al. The PRISMA statement for reporting systematic reviews and meta-analyses of studies that evaluate health care interventions: explanation and elaboration. PLoS Medicine 2009;6:e1000100.

16. Jadad AR, Moore RA, Carroll D, Jenkinson C, Reynolds DJ, Gavaghan DJ, et al. Assessing the quality of reports of randomized clinical trials: is blinding necessary? Control Clin Trials 1996;17:1-12.

17. Lu G, Ades AE. Combination of direct and indirect evidence in mixed treatment comparisons. Stat Med 2004;23:3105-24.

18. DerSimonian R, Laird N. Meta-analysis in clinical trials. Control Clin Trials 1986;7:177-88.

19. Jansen JP, Crawford B, Bergman G, Stam W. Bayesian meta-analysis of multiple treatment comparisons: an introduction to mixed treatment comparisons. Value Health 2008;11:956-64.

20. Geman S, Geman D. Stochastic relaxation, Gidds distributions and the Bayesian restoration of images. IEEE Trans Pattern Anal Mach Intell 1984;6:721-41.

21. Maini R, St. Clair EW, Breedveld F, Furst D, Kalden J, Weisman M, et al. Infliximab (chimeric anti-tumour necrosis factor alpha monoclonal antibody) versus placebo in rheumatoid arthritis patients receiving concomitant methotrexate: a randomised phase III trial. ATTRACT Study Group. Lancet 1999;354:1932-9.

22. Schiff M, Keiserman M, Codding C, Songcharoen S, Berman A, Nayiager S, et al. Efficacy and safety of abatacept or infliximab vs placebo in ATTEST: a phase III, multi-centre, randomised, double-blind, placebo-controlled study in patients with rheumatoid arthritis and an inadequate response to methotrexate. Ann Rheum Dis 2008;67:1096-103.

23. Westhovens R, Yocum D, Han J, Berman A, Strusberg I, Geusens P, et al. The safety of infliximab, combined with background treatments, among patients with rheumatoid arthritis and various comorbidities: a large, randomized, placebo-controlled trial. Arthritis Rheum 2006;54:1075-86.

24. Zhang FC, Hou Y, Huang F, Wu DH, Bao CD, Ni LQ, et al Infliximab versus placebo in rheumatoid arthritis patients receiving concomitant methotrexate: a preliminary study from China. APLAR J Rheumatol 2006;9:127-30.

25. Weinblatt ME, Kremer JM, Bankhurst AD, Bulpitt KJ, Fleischmann RM, Fox RI, et al. A trial of etanercept, a recombinant tumor necrosis factor receptor:Fc fusion protein, in patients with rheumatoid arthritis receiving methotrexate. N Engl J Med 1999;340:253-9

26. Combe B, Codreanu C, Fiocco U, Gaubitz M, Geusens PP, Kvien TK, et al. Etanercept and sulfasalazine, alone and combined, in patients with active rheumatoid arthritis despite receiving sulfasalazine: a double-blind comparison. Ann Rheum Dis 2006;65:1357-62.

27. Weinblatt ME, Keystone EC, Furst DE, Moreland LW, Weisman MH, Birbara CA, et al. Adalimumab, a fully human anti-tumor necrosis factor alpha monoclonal antibody, for the treatment of rheumatoid arthritis in patients taking concomitant methotrexate: the ARMADA trial. Arthritis Rheum 2003;48:35-45.

28. Keystone EC, Kavanaugh AF, Sharp JT, Tannenbaum H, Hua Y, Teoh LS, et al. Radiographic, clinical, and functional outcomes of treatment with adalimumab (a human anti-tumor necrosis factor monoclonal antibody) in patients with active rheumatoid arthritis receiving concomitant methotrexate therapy: a randomized, placebo-controlled, 52-week trial. Arthritis Rheum 2004;50:1400-11.

29. Kim HY, Lee SK, Song YW, Yoo DH, Koh EM, Yoo B, et al. A randomized, double-blind, placebo-controlled, phase III study of the human anti-tumor necrosis factor antibody adalimumab administered as subcutaneous injections in Korean rheumatoid arthritis patients treated with methotrexate. APLAR J Rheumatol 2007;10:9-16.

30. Furst DE, Schiff MH, Fleischmann RM, Strand V, Birbara CA, Compagnone D, et al. Adalimumab, a fully human anti tumor necrosis factor-alpha monoclonal antibody, and concomitant standard antirheumatic therapy for the treatment of rheumatoid arthritis: results of STAR (Safety Trial of Adalimumab in Rheumatoid Arthritis). J Rheumatol 2003;30:2563-71.

31. Keystone EC, Genovese MC, Klareskog L, Hsia EC, Hall ST, Miranda PC, et al. Golimumab, a human antibody to tumour necrosis factor alpha given by monthly subcutaneous injections, in active rheumatoid arthritis despite methotrexate therapy: the GO-FORWARD Study. Ann Rheum Dis 2009;68:789-96.

32. Kay J, Matteson EL, Dasgupta B, Nash P, Durez P, Hall S, et al. Golimumab in patients with active rheumatoid arthritis despite treatment with methotrexate: a randomized, double-blind, placebo-controlled, dose-ranging study. Arthritis Rheum 2008;58:964-75.

33. Cohen SB, Moreland LW, Cush JJ, Greenwald MW, Block S, Shergy WJ, et al. A multicentre, double blind, randomised, placebo controlled trial of anakinra (Kineret), a recombinant interleukin 1 receptor antagonist, in patients with rheumatoid arthritis treated with background methotrexate. Ann Rheum Dis 2004;63:1062-8.

34. Genovese MC, McKay JD, Nasonov EL, Mysler EF, da Silva NA, Alecock E, et al. Interleukin-6 receptor inhibition with tocilizumab reduces disease activity in rheumatoid arthritis with inadequate response to disease-modifying antirheumatic drugs: the tocilizumab in combination with traditional disease-modifying antirheumatic drug therapy study. Arthritis Rheum 2008;58:2968-80.

35. Smolen JS, Beaulieu A, Rubbert-Roth A, Ramos-Remus C, Rovensky J, Alecock E, et al. Effect of interleukin-6 receptor inhibition with tocilizumab in patients with rheumatoid arthritis (OPTION study): a double-blind, placebo-controlled, randomised trial. Lancet 2008;37:987-97. 
36. Maini RN, Taylor PC, Szechinski J, Pavelka K, Bröll J, Balint G, et al. Double-blind randomized controlled clinical trial of the interleukin-6 receptor antagonist, tocilizumab, in European patients with rheumatoid arthritis who had an incomplete response to methotrexate. Arthritis Rheum 2006;54:2817-29.

37. Kremer J, Fleischman R, Brzezicki J, Ambs P, Alecock E, Burgos-Vargas R, et al. Tocilizumab inhibits structural joint damage, improves physical function, and increases DAS28 remission rates in RA patients who respond inadequately to methotrexate: the LITHE study - EULAR 2009 [abstract]. Ann Rheum Dis 2009;68 Suppl 3:122.

38. Bruce B, Fries JF. The Stanford Health Assessment Questionnaire: a review of its history, issues, progress, and documentation. J Rheumatol 2003;30:167-78

39. van der Heijde DM. Overview of radiologic efficacy of new treatments. Rheum Dis Clin North Am 2004;30:285-93.
40. Chen YF, Jobanputra P, Barton P, Jowett S, Bryan S, Clark W, et al. A systematic review of the effectiveness of adalimumab, etanercept and infliximab for the treatment of rheumatoid arthritis in adults and an economic evaluation of their cost-effectiveness. Health Technol Assess 2006;10:1-229.

41. Thompson SG, Smith TC, Sharp SJ. Investigating underlying risk as a source of heterogeneity in meta-analysis. Stat Med 1997; 16:2741-58.

42. American College of Rheumatology Subcommittee on Rheumatoid Arthritis Guidelines. Guidelines for the management of rheumatoid arthritis: 2002 Update. Arthritis Rheum 2002;46:328-46.

43. French High Health Authority (HAS). Rheumatoid arthritis. Diagnosis and initial management. September 2007 [Internet. Accessed Nov 25, 2010]. Available from: http://www.has-sante.fr/ portail/jcms/c_606479/polyarthrite-rhumatoide-diagnostic-et-priseen-charge-initiale) 